Review Article

\title{
Management of Constipation through Yogic Therapy
}

\author{
Siddappa Naragatti', Preethi Bendore $^{2}$, Garima $^{3}$, NK Hiregoudar $^{4}$
}

${ }^{1}$ Yoga Therapist, ${ }^{2}$ Yoga and Naturopathy Physician, ${ }^{3}$ Senior Research Fellow, Central Council for Research in Yoga and Naturopathy, New Delhi, India.

${ }^{4}$ Director, Ojashvi Yoga Training School Rishikesh, Uttarakhand, India.

DOI: https://doi.org/10.24321/2394.6547.202104

\section{I $\quad \mathbf{N} \quad \mathbf{F} \quad \mathbf{O}$}

\section{Corresponding Author:}

Siddappa Naragatti, Central Council for Research

in Yoga and Naturopathy, New Delhi, India.

E-mail Id:

siddappa.naragatti@gmail.com

Orcid Id:

https://orcid.org/0000-0001-8644-4160

How to cite this article:

Naragattii S, Bendore P, Garima, Hiregoudar NK. Management of Constipation through Yogic Therapy. J Adv Res Ayur Yoga Unani Sidd Homeo. 2021; 8(1\&2): 18-23.

Date of Submission: 2021-04-09

Date of Acceptance: 2021-06-23

\section{$\begin{array}{llllllllllllll}\mathbf{A} & \mathbf{B} & \mathbf{S} & \mathbf{T} & \mathbf{R} & \mathbf{A} & \mathbf{C} & \mathbf{T}\end{array}$}

The purpose of this review article is to identify and analyse, the problem of constipation, its causes, symptoms, risk factors and complications arising in human life. Constipation problems were recognised by some previous empirical research. Constipation presents as a perpetual problem in health-care with painful and debilitating consequences, however, it is frequently preventable. A prerequisite to prevention is an assessment of the risk of a condition occurring so that interventions can be individualised in an attempt to prevent it. Yoga is a unique way of lifestyle management of many common health misalignments for the prevention of diseases, preservation and promotion of health. Yoga, in fact, gives due importance to different layers of existence functions for maintaining positive health example physical layer (Annamaya Khosa), pranic layer (Pranamaya Khosa), mental layer (Manomaya Khosa), scientific layer (Vigyanmaya Khosa) and blissful layer (Anandamaya Khosa). Yoga is a science of integration of human consciousness with nature. The objective experimentation is the most important aspect of searching the truth employed by modern science that searches into many practices of yoga demanding both subjective as well as objective tools for understanding the effects for further application and wider acceptance. Studies have been conducted around the world on many yoga therapies for the management of the problem of constipation i.e enema that clears the constipation and provide mental peace. This enabled subsequent work to be performed to develop a risk assessment tool for constipation that could be used in clinical practice.

Keywords: Management, Constipation, Yoga Therapy, Lifestyle

\section{Introduction}

Constipation is a modern disease ${ }^{1}$, caused by lack of exercise and yogic practices, wrong food habits, latenight eating and improper lifestyle. ${ }^{2}$ Late ingestion of food causes decomposition of food in the colon which causes indigestion, stress and strain, tiredness, gas acidity, stomach-ache, piles, loss of appetite, headache, migraine, colitis, obesity, insomnia and irregular periods in the case of females. ${ }^{3}$ Constipation can be treated by regulating and improving lifestyle and food habits ${ }^{4}$ One should eat quietly, calmly, slowly, happily, chewing tiny morsels of food and eating only when hungry, it's better to have two meals instead of having more food in one meal. One should have 
a lot of salad or fresh, sweet fruit. Each meal must contain some fibre in the form of green vegetables etc. A lot of salad should be taken before each meal. Water should be taken only after an hour or so of the meals. Supper should not include heavy meals like pulses. Dinner should be had between $7 \mathrm{pm}$ and $8 \mathrm{pm}$. Some physical exercises should be done for an hour every day like morning-walk, jogging, preferably yoga, asanas etc. As is said, early to bed, early to rise, makes a person healthy, wealthy and wise, so a person should not be awake till late hours at night.

All the diseases start from the stomach. ${ }^{5}$ When the bowels, liver and kidneys are not working well, then instead of nutrients getting absorbed in the intestines, the blood gets easily contaminated with various toxins, fat, cholesterol, and ketones leading to various health problems. ${ }^{6}$ In fact, constipation is the mother of the entire clan of diseases.

\section{Meaning and Definition}

The word, "constipation" comes from the Latin word, constipore, which means "to press, crowd together". Constipation is also known as costiveness and irregularity.

People suffering from it can neither pass stools regularly nor completely empty their bowels. In other words, constipation implies either infrequent bowel movements or a difficult passage of stools. It is a common gastrointestinal problem. ${ }^{7}$

The normal frequency for bowel movements varies from person to person. ${ }^{8}$ Most people only experience constipation for a short time. However, constipation can be a long-term condition for some, causing significant pain and discomfort, thereby affecting their quality of life. ${ }^{9}$

Constipation is defined as a condition in which an individual experiences a change in the normal bowel habits characterised by a decrease in frequency or passage of hard, dry stools, difficult defecation and sluggish action of the bowels. ${ }^{10}$

\section{Causes}

Constipation happens when the colon absorbs too much water ${ }^{11}$ or if the muscles in the colon are contracting slowly or poorly due to which the stool moves too slowly and loses more water. ${ }^{12}$ It also occurs when waste or stool moves too slowly through the digestive tract, causing it to become hard and dry.

Most cases of constipation are not caused by a specific condition. It may be difficult to identify the exact cause. ${ }^{13}$ However, the following factors increase the chance of constipation. ${ }^{14}$

- Lifestyle causes, such as lack of regular bowel habits from childhood, irregular eating times, staying awake till late at nights

- Lack of physical activity or exercise
- Psychological factors, such as worry, anxiety, fear, depression

- Dietary factors, such as taking food that contains refined products like refined flour, sweets, non-fibrous foods, non-vegetarian foods, alcohol, smoking and not drinking sufficient quantity of water

- Certain drugs, like diuretics, sleeping pills, excessive use of purgatives etc

- Ignoring the urge to have a bowel movement or delaying it

- Having limited privacy when using the toilet

- Not drinking enough fluids

- Underweight or overweight

- Certain disease conditions, such as intestinal obstruction, tumours, weakness of the intestinal muscles or excessive tonicity and anal lesions ${ }^{15}$

\section{Symptoms}

Signs and symptoms of chronic constipation include:

- Passing fewer than three stools a week

- Having lumpy or hard stools

- $\quad$ Straining to have bowel movements

- Feeling as though there's a blockage in your rectum that prevents bowel movements

- Feeling as though you can't completely empty the stool from your rectum

- Needing help to empty your rectum, such as using your hands to press on your abdomen and using a finger to remove stool from your rectum

- Constipation may be considered chronic if you've experienced two or more of these symptoms for the last three months

The symptoms and ailments from constipation are almost endless. Tension, fatigue, irritability, short temper, allergies, indigestion, headaches, nervousness, nausea, depression ${ }^{16}$, obesity, food craving, anxiety, insomnia, bad breath, menstrual problems, poor appetite, piles, skin problems, abdominal discomfort, and many other problems occur due to constipation.

\section{Types and Pathology of Constipation}

Mainly there are two types of constipation, primary and secondary. ${ }^{17}$ The altered stool consistency in primary constipation occurs due to poor diet and lack of sufficient exercises, during weaning.

The causes of secondary constipation are hypothyroidism, diabetes, diseases that affect the brain or blood vessels, such as dementia, depression, use of certain medications, and irritable bowel syndrome. ${ }^{18}$

\section{Effects of Constipation}

You cannot have sweet thoughts on a sour stomach; in fact, a foul stomach could affect the mental capabilities to 
the worst extent, reducing the memory and other faculties remarkably. ${ }^{19} \mathrm{~A}$ constipated executive cannot take quick and right decisions. In our daily experience, we have seen many persons who were brilliant once, but now suffer from extreme depression due to severe constipation. ${ }^{20}$ Constipation causes the colon to literally swell, expand, and even become herniated.

The bottom line is the secret of creating powerful health is cleaning out the eliminative organs periodically and the best place to start with is the bowel. ${ }^{21}$ This is similar to the periodic overhauling that is imperative for the efficient functioning of a machine. ${ }^{22}$

\section{Normality}

It is considered normal to have one bowel movement per day for every major meal one eats. Having normal and regular bowel movements will get the waste and sludge out of the body faster keeping a balance between consumption of food and evacuation of waste. This protects the health in the first place, also provides more energy, maintains normal weight, good vitality and helps in preventing diseases. ${ }^{23}$

\section{Risk Factors}

The following factors may increase the risk of constipation:

- $\quad$ Being an older adult

- Being a woman

- Being dehydrated

- Eating a diet that's low in fibre

- Getting little or no physical activity ${ }^{24}$

- Taking certain medications, including sedatives, opioid pain medications, antidepressants, medications to lower blood pressure and other supplements like calcium and iron

- Having a mental health condition such as depression or an eating disorder

\section{Complications}

Swollen Veins in the Anus: Straining to have a bowel movement may cause swelling in the veins in and around your anus.

Torn Skin in the Anus: A large or hard stool can cause tiny tears in the anus.

Stool that can't be Expelled: Constipation may cause an accumulation of hardened stool that gets stuck in your intestines. $^{25}$

Intestine that Protrudes from the Anus: Straining to have a bowel movement can cause a small part of rectum to stretch and protrude from the anus.

\section{Yogic Classification of Diseases}

Yoga can bring about changes in modern-day mind-body diseases. The vital life-force in the body is affected by imbalances in the breath and causes dysfunction in the five channels of life-force. ${ }^{26}$ The five channels of prana are: (1) Prana, which controls the functioning of the heart and lungs and all the activities in the chest region like breathing, swallowing, and circulation of blood; (2) Apana, which controls the function of the excretory and reproductive organs and hence is responsible for all downward activities like urination, defecation and menstruation; (3) Samana, which activates and controls proper digestion and is responsible for balancing Prana and Apana; (4) Udana, which is responsible for all upward activities such as belching and vomiting and (5) Vyana, which is responsible for all activities on the periphery like nerve impulses and cellular activity in all cells and gives an extra boost to other four channels when required. ${ }^{27}$

Due to the imbalance in the vital lifeforce caused by mental conflicts, the autonomic nervous system is disturbed and it might result in heightened bowel contractility. ${ }^{28}$ Of the five lifeforces, the most important for healthy functioning of the body is "Samana," a lifeforce that is responsible for digestion and for balancing two other major life-forces, "Apana" and "Prana." When "Samana" is disturbed, the food ingested cannot be digested properly. This leads to overdigestion, non-digestion, wrong digestion and thus improperly digested food when settles in the body leads to diseases.

\section{Yogic Breathing and Autonomic Balance}

Yoga practices offer the possibility of reducing inappropriate activation of the Autonomic Nervous System (ANS). Clinical trials on IBS patients have shown abnormalities in autonomic function and psychological profiles. ${ }^{29}$

Some studies have shown that there is increased sympathetic activity in IBS patients. Using spectral analysis of heart-rate variability in 54 subjects, it was reported that IBS patients had significantly increased sympathetic activity compared to healthy controls, whereas there was no difference in parasympathetic activity between these two groups.

\section{Research Findings}

A study conducted on the Integrated Approach of Yoga Therapy (IAYT) on chronic constipation has proved that it's effective in treating chronic constipation. ${ }^{30} \mathrm{IAYT}$ is a yogabased lifestyle intervention and a form of yoga.

It consisted of asanas, pranayama, meditation, kriyas, balanced diet, turning to nature, counselling sessions etc. This pilot study showed a significant improvement in satisfaction after intervention $(P<0.01)$.

Yoga has been used as a complementary therapy in gastrointestinal related problems such as IBS. In one of the randomised controlled studies on 22 male IBS patients, who underwent two months of yoga practice, 
a significant decrease in anxiety and sympathetic activity along with improvement in parasympathetic activity was observed at the end of the study. In another randomised controlled study, 25 adolescent IBS subjects underwent one month of yoga intervention daily for an hour and a significant improvement in gastrointestinal symptoms including pain, functional disability, coping anxiety and depression was observed in the yoga group as compared to the control group. These studies indicate the role of yoga in gastrointestinal related problems.

Studies conducted around the world have proved that yoga is beneficial for constipation. Yoga helps to boost the digestive system and works efficiently for our gut. Our gut is the epicentre of our health. ${ }^{31}$ Yoga helps to regulate our bowel movements which have become a tough task for many of us given our millennial lifestyle. ${ }^{32}$ Yoga can benefit constipation problems in many ways by working on causative factors. ${ }^{33}$ It reduces stress, yoga postures stimulate the abdominal area and energises it to function better. ${ }^{34}$ The yoga asanas or poses involves bending and twisting of the body that activates our digestive tract. Yoga for constipation is the best natural way to bring relief. ${ }^{35}$ It is an effective and powerful alternate therapy to relieve the problem. Practising yoga can boost your digestion, strengthen your muscles, give a massage to your digestive organs and initiate a regular bowel movement.

Constipation is the reduction of bowel movements to three or fewer times per week. ${ }^{14}$ It is one of the most common functional gastrointestinal disorders ${ }^{36}$ prevalent all over the world. $2-27 \%$ of the world's population is affected by chronic constipation. It is more prevalent in western countries which account for $30 \%$ as compared to eastern countries ${ }^{37}$ that account for $11 \%$.

\section{Yoga as a Therapy}

Yogic practice is holistic living, it means conscious correct living in every moment. Each moment requires peculiar, conscious control and transformation of what is not desired or is harmful such as negative attitudes, habits detrimental to health, unconscious drives and movements. Yoga regulates physical, emotional and mental activity while constantly evolving the mind to higher states of consciousness. Further yoga aspires to take every human being to a state of consciousness that is beyond stress and is free from all conflicts, a balanced but detached way of living at the material level while living within or in a state of consciousness guided by love, energy awareness and harmony. "Yoga is self-conscious finding". A lifestyle and living if regulated by a higher state of consciousness which itself is full of love, delight, peace, harmony, wisdom and truth will bring about a transformation in individual, health, prevention and management of disease, will come as by-products.
Regular practice of yoga for an hour daily is proven very beneficial. It should include sukhamavyayam or suryanamaskara and asana practices along with breathing thatshould include bending, twisting postures like pawanamuktasan, halasana, dhanurasana, ardhamatsyendrasana, baddhakonasana, bhujangasan, vajrasana, paschimottanasana, padahastasana and shalabhasan etc. Minimum five asanas may be selected and practised depending upon the flexibility and constitution of the body.

The practice of laghu-shankaprakshalan/ shankhaprakshalan kriya twice a year is very useful. Pranayamas like kapalabhati (kriya), alternate nostril breathing (anulomvilom), ujjayi, shitkari, sheetali and bhramari practices should be practised for 10 min after asanas. Relaxation technique should be practised for five to ten minutes followed by meditation for twenty minutes.

This gives them a feeling of self-control and calmness leading to relaxation and health. The popularity of yoga is evident with a prevalence of $8.7 \%$ yoga practitioners in $2012^{38}$ within the USA that is equivalent to 20 million adults. It has also been found that women practitioners outweigh males by a ratio of almost 4:1.

\section{Conclusion}

Yoga is a way of life and living which demands conscious effort on the part of the practitioner. This conscious effort brings changes in the whole personality, attitude and lifestyle. It is in fact a way of transformation of life, mind, and body and works wonders in this chronic problem of constipation. Many studies have proved that yoga is an excellent and natural remedy for gastrointestinal problems including chronic constipation.

\section{Conflict of Interest: None}

\section{References}

1. Dehghani SM, Bahroloolomifard MS, Yousefi G, Pasdaran A, Hamedi A. A randomized controlled double blinded trial to evaluate efficacy of oral administration of black strap molasses (sugarcane extract) in comparison with polyethylene glycol on pediatric functional constipation. JEthnopharmacol. 2019;238:111845. [PubMed] [Google Scholar]

2. McKenzie YA, Bowyer RK, Leach H, Gulia P, Horobin J, O'Sullivan NA, Pettitt C, Reeves LB, Seamark L, Willams M, Thompson J, LomerMCE;IBS Dietetic Guideline Review Group on behalf of Gastroenterology Specialist Group of the British Dietetic Association. British Dietetic Association systematic review and evidence-based practice guidelines for the dietary management of irritable bowel syndrome in adults (2016 update). J HumNutrDiet. 2016;29(5):549-75. [PubMed] [Google Scholar]

3. Gawron LM, Goldberger A, Gawron AJ, Hammond C, 
Keefer L. The impact of hormonal contraception on disease-related cyclical symptoms in women with inflammatory bowel diseases. InflammBowel Dis. 2014;20(10):1729-33. [PubMed] [Google Scholar]

4. Webster L, Chey WD, Tack J, Lappalainen J, Diva U, Sostek M. Randomised clinical trial: the long-term safety and tolerability of naloxegol in patients with pain and opioid-induced constipation. AlimentPharmacolTher. 2014;40(7):77179. [PubMed] [Google Scholar]

5. Wallace RK. The Microbiome in Health and Disease from the Perspective of Modern Medicine and Ayurveda. Medicina. 2020;56(9):462. [PubMed] [Google Scholar]

6. Castillo-Rodriguez E, Fernandez-Prado R, Esteras R, Perez-Gomez MV, Gracia-Iguacel C, FernandezFernandez B,Kanbay M, Tejedor A, Lazaro A, Ruiz-Ortega M, Gonzalez-Parra E, Sanz AB, Ortiz A, Sanchez-Niño MD. Impact of altered intestinal microbiota on chronic kidney disease progression. Toxins. 2018;10(7):300. [PubMed] [Google Scholar]

7. Motaharifard MS, Jafari Z, Paknejad MS, Oveidzadeh $\mathrm{L}$, Karimi M. Prevention and treatment of constipation in children from the perspective of Iranian traditional medicine. JIntegrMed. 2016;14(6):429-35. [PubMed] [Google Scholar]

8. Rojjanadumrongkul K, Kumthip K, Khamrin $\mathrm{P}$, Ukarapol N, Ushijima H, Maneekarn N. Enterovirus infections in pediatric patients hospitalized with acute gastroenteritis in Chiang Mai, Thailand, 20152018. PeerJ. 2020;8:e9645. [PubMed] [Google Scholar]

9. De Giorgio R, Ruggeri E, Stanghellini V, Eusebi LH, Bazzoli F, Chiarioni G. Chronic constipation in the elderly: a primer for the gastroenterologist. BMC Gastroenterol. 2015;15(1):130. [PubMed] [Google Scholar]

10. Schuster BG, Kosar L, Kamrul R. Constipation in older adults: stepwise approach to keep things moving. Can Fam Physician. 2015;61(2):152-8.[PubMed] [Google Scholar]

11. Bartlett A, Gullickson RG, Singh R, Ro S, Omaye ST. The Link between Oral and Gut Microbiota in Inflammatory Bowel Disease and a Synopsis of Potential Salivary Biomarkers. Appl Sci. 2020;10(18):6421. [Google Scholar]

12. Wojtunik-Kulesza K, Oniszczuk A, Oniszczuk T, Combrzyński M, Nowakowska D, Matwijczuk A. Influence of in vitro digestion on composition, bioaccessibility and antioxidant activity of food polyphenols-A non-systematic review. Nutrients. 2020;12(5):1401. [PubMed] [Google Scholar]

13. Okuyan CB, Bilgili N. Effect of abdominal massage on constipation and quality of life in older adults: A randomized controlled trial. ComplementTherMed. 2019;47:102219.[PubMed] [Google Scholar]

14. Alsalimy N, Madi L, Awaisu A. Efficacy and safety of laxatives for chronic constipation in longterm care settings: A systematic review. JClin PharmTher. 2018;43(5):595-605.[PubMed] [Google Scholar]

15. Kabbash MM, Saleem AE, Abdel Rheem OA, El-Rahman A, Adly MA. Surgical Intervention in Adhesive Intestinal Obstruction. Egypt J Hosp Med. 2019;77(6):5954-7. [Google Scholar]

16. Moreno MTN, de Araújo CA. Emoções de raivaassociadas à gastrite e esofagite. Mudanças-Psicologia da saúde. 2009;13(1):30-87.[Google Scholar]

17. De Giorgio R, Ruggeri E, Stanghellini V, Eusebi LH, Bazzoli F, Chiarioni G. Chronic constipation in the elderly: a primer for the gastroenterologist. BMC Gastroenterol. 2015;15(1):130.[PubMed] [Google Scholar]

18. Locke GR III, Pemberton JH, Phillips SF. AGA technical review on constipation. American Gastroenterological Association. Gastroenterology. 2000;119(6):1766-78. [PubMed]

19. Nagar I. Self-Regulation for sustaining happiness and well-being: An Indian perspective. Psycholog Stud. 2018;63(2):181-6.[Google Scholar]

20. Forootan M, Bagheri N, Darvishi M. Chronic constipation: A review of literature. Medicine. 2018;97(20):e10631. [PubMed] [Google Scholar]

21. Wang JC, Sung FC, Men M, Wang KA, Lin CL, Kao CH. Bidirectional association between fibromyalgia and gastroesophageal reflux disease: two population-based retrospective cohort analysis. Pain. 2017;158(10):19718.[PubMed] [Google Scholar]

22. Mowat AM, Agace WW. Regional specialization within the intestinal immune system. Nat Rev Immunol. 2014;14(10):667-85.[PubMed] [Google Scholar]

23. Mason P, Lang T. Sustainable diets: how ecological nutrition can transform consumption and the food system. 1st ed. Taylor \& Francis; 2017.[Google Scholar]

24. Usmani SA, Reckenberg K, Johnson O, Stranges PM, Teshome BF, Kebodeaux CD, Vouri SM. Relative risk of adverse events and treatment discontinuations between older and non-older adults treated with antimuscarinics for overactive bladder: a systematic review and meta-analysis. Drugs Aging. 2019;36(7):63945.[PubMed] [Google Scholar]

25. McQuade RM, Stojanovska V, Abalo R, Bornstein JC, Nurgali K. Chemotherapy-induced constipation and diarrhea: pathophysiology, current and emerging treatments. FrontPharmacol. 2016;7:414.[PubMed] 
[Google Scholar]

26. Labanski A, Langhorst J, Engler H, Elsenbruch S. Stress and the brain-gut axis in functional and chronic-inflammatory gastrointestinal diseases: A transdisciplinary challenge. Psychoneuroendocrinology. 2020;111:104501. [PubMed] [Google Scholar]

27. Sharma P, Poojary G, Dwivedi SN, Deepak KK. Effect of yoga-based intervention in patients with inflammatory bowel disease. IntJYoga Therap. 2015;25(1):101-12. [PubMed] [Google Scholar]

28. Sharkey KA, Beck PL, McKay DM. Neuroimmuno physiology of the gut: Advances and emerging concepts focusing on the epithelium. NatRev GastroenterolHepatol. 2018;15(12):765-84.[PubMed] [Google Scholar]

29. Schedlowski M, Enck P, Rief W, Bingel U. Neuro-biobehavioral mechanisms of placebo and nocebo responses: implications for clinical trials and clinical practice. PharmacolRev. 2015;67(3):697-730.[PubMed] [Google Scholar]

30. Rao J, Metri KG, Singh A, Nagaratna R.Effect of Integrated Approach of Yoga Therapy on Chronic Constipation. Voice Res.2016;5(1):23-6. [Google Scholar]

31. Bazzano AN, Anderson CE, Hylton C, Gustat J. Effect of mindfulness and yoga on quality of life for elementary school students and teachers: results of a randomized controlled school-based study. Psychol Res BehavManag.2018;11:81-9. [PubMed] [Google Scholar]

32. Daruwalla SP.Mindfulness for the Millennial Generation: A Clinician's Handbook for College CounselingCenters[dissertation].Wright State University CORE Scholar; 2011.[Google Scholar]

33. Gan Y, Liang J, Diao W, Zhou X, Mu J, Pang L, Tan F, Zhao X. Lactobacillus plantarum KSFY06 and geniposide counteract montmorillonite-induced constipation in Kunming mice. Food Sci Nutr. 2020;8(9):5128-37. [PubMed] [Google Scholar]

34. Wang L, Li CX, Tian Y, Ye JW, Li F, Tong WD. Abdominal ventral rectopexy with colectomy for obstructed defecation syndrome: An alternative option for selected patients. World JClinCases. 2020;8(23):5976-87. [PubMed] [Google Scholar]

35. Corsello A, Pugliese D, Gasbarrini A, Armuzzi A. Diet and Nutrients in Gastrointestinal Chronic Diseases. N utrients. 2020;12(9):2693. [PubMed] [Google Scholar]

36. Ghoshal UC, Singh R, Chang FY, Hou X, Wong BC.Kachintorn U; Functional Dyspepsia Consensus Team of the Asian Neuro gastroenterology and Motility Association and the Asian Pacific Association of Gastroenterology. Epidemiology of uninvestigated and functional dyspepsia in Asia: facts and fiction. JN eurogastroenterolMotil. 2011;17(3):235.[PubMed]
[Google Scholar]

37. Gulati K, Bhargav PH, Abraham SE, Bhargav H. Yoga: A Multi-Dimensional Therapeutic Approach to Autism Spectrum Disorder. In: Handbook of Research on Evidence-Based Perspectives on the Psychophysiology of Yoga and Its Applications. IGI Global; 2021. p. 361-90.

38. Kavuri V, Selvan P, Malamud A, Raghuram N, Selvan SR. Remedial yoga module remarkably improves symptoms in irritable bowel syndrome patients: A 12-week randomized controlled trial. EurJIntegMed. 2015;7(6):595608.[Google Scholar] 